\title{
El mercado: mundos teóricos y mundos prácticos
}

\author{
Natalia Ribas Mateos \\ Universidad de A Coruña \\ mazo@arquired.es
}

\begin{abstract}
Resumen
A partir de una breve revisión de algunas teorias clásicas sobre el empresariado étnico, el artículo desarrolla una descripción etnográfica de este tipo de empresariado en los mercados. Para ello se centra en el espacio del mercado de Les Glòries, en la ciudad de Barcelona, y toma como referencia una comunidad de inmigrantes: los marroquies en Cataluña. Destaca especialmente la conformación espacial del mercado como expresión de la trayectoria de esta comunidad en Cataluna, que permite distinguir distintos tipos de empresarios distribuidos de forma desigual en el mercado, en función de las prácticas formales o informales de venta.

Palabras clave: empresariado, mercado, espacio, marroquies, reciprocidad, economía informal
\end{abstract}

\begin{abstract}
Through a brief review of some of the classic theories regarding ethnic entrepreneurship, this article makes an ethnographic description of what the ethnic entrepreneur means to the markets. To do so, the article focuses on the market of Les Glories in the city of Barcelona and uses the immigrant Moroccan community in Catalonia as a reference. It places particular emphasis on the spatial structure of the market as an expression of the trajectory of the Moroccans in Catalonia and distinguishes different types of entrepreneur who are distributed unevenly both across the market and across formal and informal sales practices.
\end{abstract} Key words: entrepreneurship, market, space, Moroccans, reciprocity, informal economy 


\section{Sobre el interés del empresariado étnico en el mercado}

Los ocho primeros años del siglo XXI (2000-2007) se han caracterizado por un gran incremento de los flujos de extranjeros en España. En efecto, esos flujos migratorios experimentaron un salto a principios del siglo XXI (concretamente entre 1999 y 2000) $y$, desde entonces, con un leve descenso en 2003, no han dejado de crecer. Por tanto, lo han hecho con especial ímpetu en dos fechas: en 2000 y 2004. En el año que inauguró el siglo se pasó de alrededor de 67.000 altas anuales de residencia en los municipios españoles a rozar las 300.000. En la segunda fecha se rebasaron las 550.000, y en 2006, las 650.000. Los datos de 2007 hablan de 800.000 altas en el padrón, un verdadero récord, si bien habría que descontar los retornos o reemigraciones y depurar su magnitud con datos más asentados y definitivos. En resumen, la pendiente podrá ser más o menos inclinada, pero lo cierto es que el crecimiento impetuoso y desajustado es un hecho innegable durante los siete últimos años (Escribano y Suárez, 2007). Evidentemente, los flujos de inmigrantes son de naturaleza y carácter muy diversos. Los hay temporales y duraderos, pero lo que nos interesa aquí es comprender esos distintos proyectos, según si se trata de proyectos económicos autónomos o buscan el asentamiento de las familias inmigrantes, principalmente en la zona del espacio mediterráneo. En esta fase de consolidación destacan en España tres grandes comunidades de inmigrantes: marroquíes, ecuatorianos y rumanos. En este artículo nos vamos a centrar especialmente en los primeros.

Desde una perspectiva histórica, pues, la inmigración en España ha cambiado en gran medida tanto en la velocidad como en la forma y en el fondo. En este contexto, las áreas metropolitanas de Madrid y Barcelona, los barrios de los centros históricos - como Lavapiés, en Madrid, y el Raval, en Barcelona- y también de las ciudades dormitorio, empiezan a constituirse en barrios donde residen muy diversas comunidades de inmigrantes, al igual que ha sucedido con otras zonas metropolitanas de sólida tradición migratoria en otros emplazamientos de la geografía europea. Se trata de lugares donde mercancías, personas y formas de hacer de remotos lugares del mundo se funden en el bullicio de la vida urbana, donde conviven sabores latinoamericanos, senegaleses, marroquíes y asiáticos, que se mezclan con tascas y pequeñas tiendas.

Carnicerías halal, teterías árabes, colmados al estilo latinoamericano, locutorios pakistaníes y centros de envío de dinero, tiendas de talla de madera y peluquerías senegalesas, comercios chinos de venta de bolsos, ropa al por mayor, tiendas de regalos y las diversas transformaciones de las tiendas de «todo a 100» son las nuevas imágenes que arropan la vida urbana. $Y$ por doquier una fuerte presencia extranjera en los mercadillos. Vendedores y clientes co-étnicos, o simplemente jóvenes autóctonos, ávidos de un consumo cosmopolita, conviven en dichos barrios, que no siempre representan 
un espacio de intercambio cultural. Con frecuencia, las poblaciones comerciantes envejecidas y faltas de relevo generacional, o que han huido por diversas razones de estos barrios a zonas más gentrificadas, alquilan sus locales a los inmigrantes, que suelen proponer buenas ofertas por sus establecimientos.

La proliferación de comercios que ofrecen productos «exóticos» o que, simplemente, son propiedad de inmigrantes es uno de los principales indicadores que visibilizan la presencia multiétnica actual en el espacio urbano de las principales ciudades españolas, así como los cambios en el consumo «exótico» por parte de determinados grupos de las clases medias urbanas. No obstante, el interés científico por esta problemática social tuvo sus orígenes al otro lado del Atlántico. De hecho, el considerable incremento de pequeños empresarios entre la población emigrante, tanto en Estados Unidos como en el norte de Europa, fue lo que estimuló el debate sobre el empresariado étnico.

El contexto general de esta transformación viene marcado por el paso de una sociedad industrial a una sociedad postindustrial y global; en él se han considerado no sólo los elementos de transición entre una sociedad y la otra, sino también los que permanecen en ellas. Es en este marco donde surge el interés por la pervivencia, la transformación y la adaptación de dispositivos de reciprocidad característicos de la sociedad preindustrial. Las prácticas recíprocas, como se manifiestan en la emergencia del empresariado étnico, son ejemplos de la capacidad de adaptación de las redes de reciprocidad en tensión con las prácticas individualizadoras de corte asociativo. La línea de investigación centrada en el empresariado étnico aborda el grupo, más allá del interés individual de sus miembros, al tiempo que analiza cómo ese grupo logra adaptarse a un contexto capitalista contemporáneo.

En la sociología de las migraciones, y en el contexto de la sociología económica, hallamos una extensa gama de teorías y casos empíricos aplicados que subrayan el papel del empresariado étnico como estrategia de movilidad en la estructura social del capitalismo avanzado. En primer lugar, cabe aludir a las teorías del intermediario (middleman), que constituyen el precedente en este tipo de estudios y prestan atención prioritaria a las dinámicas de los pequeños negocios como forma de incorporación a la sociedad receptora (Bonacich, 1972). En segundo lugar, las teorías del enclave étnico analizan la solidaridad interna como el elemento clave que facilita la incorporación al mercado de trabajo. Tradicionalmente, las condiciones en el país de origen (como las condiciones económico-políticas) y en el país de destino (cultura, clase social y habilidades obtenidas) se han considerado factores clave que estructuran la incorporación de los inmigrantes en la sociedad de la recepción. Yendo más allá de las relaciones bipolares entre origen y destino, nos preguntamos por el enclave étnico como modo de incorporación. 
Lejos de considerarlo una madriguera de explotación, el enclave étnico nos permite analizar el empresariado étnico como motor empresarial, como una escalera de movilidad social con un gran potencial de integración en la sociedad de acogida. Esta línea desarrollada por Wilson y Portes (1980) permitió cuestionar la hipótesis hasta entonces aceptada según la cual el enclave étnico era un espacio de explotación, y pasar a considerarlo un espacio de aprendizaje. Desde entonces, el debate académico sobre las empresas étnicas no ha hecho más que acrecentarse. Según Wilson y Portes, la economía étnica constituía una vía de ascenso social para los inmigrantes que difícilmente encontraban una posibilidad de movilidad social en el mercado secundario autóctono. $\mathrm{Su}$ estudio sobre el enclave de inmigrantes cubanos de Miami mostraba que los inmigrantes empleados por sus compatriotas se hallaban en mejor posición que los que trabajaban en el sector secundario autóctono. Pese a los bajos salarios, los inmigrantes aceptaban trabajar en la economía de enclave durante una temporada, lo que les permitía aprender la profesión para, posteriormente, poder establecerse por cuenta propia e iniciar su propio ascenso social.

En tercer lugar, el advenimiento de la sociedad postindustrial y la nueva división internacional del trabajo han traído consigo un descenso progresivo del empleo en el sector industrial, donde tradicionalmente se ocupaban los inmigrantes, en beneficio de una progresiva terciarización y cualificación del trabajo. Se alude entonces al paso de un modelo fordista típico de las migraciones «ordenadas» a un modelo postfordista. En este marco, son múltiples las investigaciones que ponen de relieve cómo el desarrollo del empresariado étnico en los países tradicionales de inmigración responde a una estrategia de movilidad social de los inmigrantes, ante la crisis del sector secundario y las limitadas oportunidades de empleo no cualificado en el sector servicios. La nueva reestructuración económica, pues, ha determinado el crecimiento del empresariado étnico, lo que ha favorecido el interés académico y político por este fenómeno. Situar el empresariado étnico en el centro de interés de la investigación europea en materia de migraciones internacionales ha supuesto, asimismo, dar un paso adelante para plantear una perspectiva positiva de las migraciones, contrapuesta a la visión victimizada del inmigrante (vinculada a la exclusión social, la marginación y la criminalidad). Es esta imagen diferente la que permite considerar al empresariado étnico como vía de integración social, de incorporación y de inserción exitosa (en el sentido de reconocimiento social).

En cuarto lugar, aparecen las teorías estructurales, que subrayan los factores externos, especialmente centrados en las teorías duales del mercado de trabajo. Éstas argumentan que la exclusión socioeconómica de los emigrantes, especialmente en el mercado de trabajo, les conduce a buscar otro tipo de recursos. De nuevo, como en las teorías del intermediario, se pone el acento en las limitadas oportunidades y las 
peculiaridades de la estructura económica, en lugar de centrar el debate en las características culturales del grupo (Bonacich, 1972).

Por último, el enfoque del social mix-embeddedness ha abierto una vía de análisis en el punto de encuentro entre la economía y la etnicidad. Este tipo de argumentos intentan combinar diferentes factores (estructurales, sociales y personales), interrelacionando las condiciones económicas urbanas con los condicionantes político-institucionales (Rath, 2000). Los nichos laborales se desarrollarían aquí en interacción con los grupos y su contexto social, donde la inclusión en las redes sociales adquiere una relevancia fundamental. De este modo, el tipo de economía, el tipo de Estado del bienestar al que nos refiramos, así como las características del grupo, conformarían los factores contextuales que permiten la comprensión de la movilidad social utilizando la estrategia del empresariado étnico.

En la actualidad, las redes étnicas no sólo aportan ventajas a nivel local, sino que, en el marco del proceso de globalización económica, se organizan, además, en comunidades globales. Así, son cada vez más las personas implicadas en las redes étnicas en una geografía transnacional. Estas redes operan gracias al carácter casi instantáneo de las comunicaciones, a través del espacio.

El análisis de las redes sociales permite captar las relaciones dinámicas de las migraciones, más allá de la organización de los inmigrantes en comunidades cerradas. En los estudios sobre redes sociales destacan habitualmente las formas de confianza mutua y de solidaridad interna, herederas de Polanyi (1989), es decir, de aquellos trabajos que priorizan los comportamientos de reciprocidad basados en redes de parentesco y de vecindad, aludiendo a la teoría de los vínculos fuertes y de los vínculos débiles y a la frecuencia del contacto. Destacan, desde esta perspectiva, los trabajos que examinan las posibilidades de contacto y empleo entre las redes de parentesco y amistad, dentro del debate sobre la definición de la fuerza del vínculo social (Granovetter, 1974).

En el presente artículo intentaremos aplicar algunas de esas reflexiones teóricas al caso del mercado, valorando cómo los recursos étnicos (aquí en contraste con lo autóctono, la extranjería y las identidades nacionales) pueden ser complementarios de los recursos de clase y cómo pueden convertirse, asimismo, en importantes recursos para las estrategias de supervivencia, más allá de la consideración exclusivamente «exótica» de los productos en venta y de la presencia de una clientela exclusivamente co-étnica. 


\section{Del zoco al mercado de Les Glòries}

Cabe suponer que los mercaderes marroquíes conocen bien el mundo del mercado tradicional, debido a la importancia que tiene el zoco en sus lugares de origen.

La palabra «zoco» tiene su origen en el acaciano souk, término que vendría a designar vagamente el conjunto de calles de una población. Posteriormente, el arameo la adoptaría como suq, que se podría traducir, en parte, por el concepto griego y romano de ágora. En la lengua árabe (plural asuaq), esta palabra se utilizó antiguamente para referirse al lugar donde se vendían los animales. La transformación de estos espacios económicos en mercados dentro de un complejo arquitectural tuvo lugar tardíamente, por iniciativa del califa omeya Hicham Abd al Malik. A partir de ese momento pasó a designar el contexto topográfico donde se concentran las actividades artesanales y comerciales (Mermier, 2005).

Con el tiempo, el zoco se configuró como un espacio muy relevante en las ciudades árabes tradicionales y, como consecuencia, se convirtió en manifestación de dos de los principales criterios de urbanidad: la heterogeneidad social de la población y la organización económica de actividades diversas.

Uno de los textos más interesantes a este respecto, por cuanto aporta un análisis detallado (en el espacio y en el tiempo) del funcionamiento de un zoco (aunque el autor utiliza la palabra «bazar») y de su importancia como institución social, es el del antropólogo Geertz, que se centra en el caso del zoco de Sefrou, en Marruecos. El autor parte de la idea de que el bazar no es sólo una forma cultural, sino también una institución social y un tipo económico. Su objetivo de investigación fue buscar un tipo ideal a partir de esa economía del zoco, que tendría sus propias lógicas de racionalidad y legitimidad.

Esta noción del zoco, o bien de la economía de bazar, entronca con la teoría neoclásica del mercado y se relaciona con cuestiones de sociología económica de corte weberiano, así como con elementos vinculados al concepto de «reciprocidad» de Polanyi. $\mathrm{Al}$ elegir este enfoque antropológico, Geertz presenta el zoco como una institución donde confluyen una larga serie de condicionamientos históricos, redes sociales y matrices culturales.

En primer lugar, la etnografía de Geertz nos ofrece algunas descripciones interesantes del funcionamiento del zoco: predominio del pequeño negocio con una división extrema del trabajo; ausencia de estandarización de los productos, así como del peso y la medida; débil control gubernamental; ausencia de coordinación jerárquica entre los negocios; preferencia por las relaciones de partenariado; hipertrofia de las competencias de negociación en relación con las técnicas de gestión; y relaciones entre patrones, 
obreros y aprendices que se muestran más como formas de ayuda que como formas de explotación.

El orden social se presenta como un «orden negociado». Las personas utilizan identidades múltiples que se incorporan al repertorio de recursos que pueden movilizarse para establecer vínculos personales, circular en las redes de relaciones y desarrollar acciones estratégicas. Los actores, pese a pertenecer a una serie de clasificaciones de referencia (por ejemplo, profesional o confesional), cuentan con cierta flexibilidad, sobre la que operan criterios como la proximidad residencial, la sociabilidad informal, la ayuda mutua, la cooperación ritual y las alianzas familias, pero también con un margen de maniobra que les permite no tener comportamientos rígidos imbuidos por una lógica estructural. De esta forma, la tribu, la cofradía o la corporación no son instituciones totales (Geertz, 2005:35).

\section{El espacio del mercado de Les Glòries ${ }^{1}$}

El mercado de los Encantes de Barcelona, el Rastro de toda la vida de esta ciudad, encarna una de las formas de comercio étnico propias de los marroquíes que se desarrolla en la Ciudad Condal desde principios de 1990. Pero hay más:

a) La concentración de pequeños negocios en el barrio del Raval.

b) La concentración relativa en algunas calles concretas de algunas ciudades y barrios: 1'Hospitalet, Poble Sec, Santa Caterina, etc.

c) La dispersión de pequeños negocios en múltiples barrios de la ciudad: especialmente carnicerías halal, cafeterías, locutorios y restaurantes chinos.

d) El espacio del mercado: desde los puestos fijos hasta la venta ambulante.

Estos cuatro polos constituyen las diversas formas que adopta el negocio étnico en la ciudad. La última de ellas nos parece especialmente relevante, en tanto que supone la inserción del colectivo de extranjeros más importante de Cataluña, los marroquíes, que muchas veces traen consigo formas de mercadeo diferentes de las que se establecen en los comercios de tiendas.

Los mercados semanales, sus vendedores y, sobre todo, su clientela, siguen los pasos de la inserción de los inmigrantes marroquíes en la geografía catalana. ${ }^{2}$ En este sentido,

1 En este epígrafe se utiliza como referencia una etnografía fechada a principios de 2004, dirigida por Laura Oso Casas y realizada en el marco de una investigación sobre el empresariado étnico en España.

2 Para situar en el tiempo este proceso, nos debemos remontar a los pioneros de la inmigración. En Barcelona, los primeros registros (inscritos en el Consulado de Madrid) datan de la primera mitad de la década de 1960 (1962-1965). Un seguimiento de la documentación consular marroquí entre 1926 y 1991 permite observar la extensión del asenta- 
constituyen una clara expresión de las arterias vivas de los espacios de relación de los marroquíes en Cataluña. El espacio que ocupan en estos mercados me parece muy significativo, por el hecho de que forman parte de la primera comunidad de extranjeros en España; además, se trata de una de las comunidades que podríamos calificar de históricas.

Los marroquíes que trabajan en los mercados catalanes se insertan como autónomos en un tipo de economía distinta de las formas de economía dominante. Son pequeños empresarios que trabajan con márgenes de beneficio más bajos y precios inferiores a los de las grandes superficies. En una época dominada por formas económicas sumamente rígidas, a través de los mercados, tanto vendedores como clientes buscan formas más flexibles de intercambio de mercancías. Se trata de dos mundos contrapuestos, pese a que puedan utilizar los mismos proveedores y almacenes que utilizan los mayoristas. A diferencia del sistema comercial que se establece, por ejemplo, en las grandes superficies, son ellos mismos, los empresarios ambulantes, quienes desarrollan todo el proceso: recogen la mercancía, la clasifican, la organizan, la transportan, la distribuyen, la venden, etc. Y son ellos, o son sus coétnicos, los que se implican en todo ese proceso. No cuentan con ningún tipo de ayuda, ni oficial, ni formal, ni informal. En definitiva, su actividad supone un verdadero corte entre la economía capitalista imperante y la economía de los mercados.

A pesar de tratarse de pequeños negocios, que no precisan de mucha mano de obra, estos emprendedores se insertan en una economía étnicamente controlada: los autoempleados y empleadores, sus trabajadores familiares y sus empleados coétnicos se organizan conjuntamente. Dentro de este mundo de relaciones coétnicas, la familia - muchas veces la pareja, y también su descendencia - ofrece la propia fuerza de trabajo para prosperar en los límites que impone el proyecto migratorio familiar. El trabajo en los mercados se caracteriza, además, por ser muy heterogéneo, pues recoge trazos de los subsectores formal, informal e ilegal, bajo distintas formas. Algunos vendedores sustituyen y complementan a los antiguos mercaderes; otros, por el contrario, crean nuevas centralidades urbanas y revitalizan en cierta medida, de forma espontánea, distintas partes de la ciudad. De hecho, en muchas ocasiones son exponentes de las transformaciones de ciertos barrios. De este modo, se integran de formas distintas en cadenas globales de producción y distribución. Respecto a la distribución, destaca el hecho de que muchos realizan una distribución de productos comprados a mayoristas. A este respecto, cabe apuntar la importante presencia de los inmigrantes chinos como mayoristas.

miento marroquí en Cataluña en forma de mancha de aceite. Se parte del municipio de Barcelona, donde en la primera mitad de la década de 1970 se acumulaba el 72\% de las inscripciones. El resto se concentraba en los alrededores, en el propio Barcelonès (Badalona y Sant Adrià del Besós), en el Baix Llobregat (Sant Boi y Molins de Rei) o, un poco más lejos, en el Maresme norte (Calella) (TEIM, 1994: 147). 
Se opta por el mercado de forma relativamente libre, pero se elige también porque es el lugar que el mercado de trabajo asigna en la sociedad de acogida a los inmigrantes. Los autónomos se insertan en estos mercados como la mejor opción posible en la estructura de oportunidades. Respecto a la temporalidad del proyecto, por lo general el trabajo por cuenta propia se constituye como la parada final de la trayectoria de la movilidad laboral, donde no todos aspiran a la apertura de tiendas.

En algunos mercados, como el de Les Glòries, es interesante observar cómo se entablan relaciones cosmopolitas insertas en el arte del regateo, dominado por la oralidad y las relaciones cara a cara. Destaca también en estos mercados el conocido «negocio de la maleta en el espacio euromediterráneo», como sucede entre Barcelona-GironaPerpiñán.

Los mercados son, además, resultado de la expresión espacial de las cadenas migratorias - de las antiguas dentro del mercado, de las nuevas fuera de él, en la plaza exterior-, como ocurre en el caso de Les Glòries. A pesar de dicha oposición, se abren múltiples mercados, y con ellos un mundo articulado a partir de una continua circulación de mercancías.

En el mundo del mercado, como espacio público por excelencia, se cuestionan y se reinterpretan los códigos de la moral musulmana; una moral que unas veces justifica al empresario y que otras le contesta; una moral que sirve de base para variados análisis sobre la interpretación de la capacidad de negociación y el modo de mando: quién accede y quién decide, cómo, cuándo, dónde y de quién depende. La familia es con frecuencia el núcleo de referencia de las relaciones laborales. Así, en el seno familiar, al igual que en el mercado, se confunden los roles.

El análisis de la movilidad social dentro de cada trayectoria de mercado es variopinto, en función de los orígenes, las historias migratorias y el estatus alcanzado. Entre los diferentes profesionales, los anticuarios son al parecer los que gozan de mayor estatus. La opción de la movilidad hacia el mercado no siempre es resultado de un ex puesto de asalariado, sino que a menudo es una opción resultante de la fuerte discriminación que viven los marroquíes en el trabajo asalariado. Así, muchas veces no supone un peldaño, sino la única puerta accesible; es el caso de todos aquellos cuya vida cotidiana se mueve entre la venta ambulante y la presión policial. Algunos son sedentarios, otros son semanalmente móviles, y otros son incluso transfronterizos, fenómeno que sólo se constata en el caso de los marroquíes.

La ciudad de Barcelona cuenta con 41 mercados cubiertos, entre los que cabe destacar el de los Encants Vells, ubicado en la isla configurada por las calles Cartagena, Consell de Cent y Dos de Maig con Diagonal-Glòries. La singularidad de este mercado es que en él se pueden encontrar todo tipo de productos, tanto nuevos como de 
primera mano; además, el regateo se presenta como la forma habitual de relación entre compradores y vendedores.

El lugar que Ildefons Cerdà había imaginado como el centro de la ciudad, la plaza de Les Glòries Catalanes, se convirtió a principios del año 2000 en un lugar maldito, sin definición, en un callejón sin salida que empeora tras la intervención de los urbanistas. A primera hora, los vendedores se sitúan alrededor del mercado de Bellcaire y hacia las ocho de la mañana comienzan a instalarse en la plaza, en la anilla interior de la plaza de Les Glòries. Este mercado informal nació hace cuatro años (previos a la etnografía) en una zona entre la calle Bolivia y la Meridiana, cerca del mercado de los Encants. Con posterioridad se trasladaron a la zona del Bosquet, hasta que las autoridades se lo negaron; negativa que se tradujo en sucesivas redadas policiales en otoño de ese año que en un primer momento resultaron infructuosas. Unos meses después, el Ayuntamiento cerró todo el perímetro del Bosquet para impedir la salida de los mercaderes y llevó a cabo una gran redada policial, que acabó con ese mercado informal. ${ }^{3}$

Ahora, al estar instalados dentro de la anilla de Les Glòries, los vendedores tienen mayor movilidad para salir corriendo, como sucede a diario. Muchos de los productos que se venden son objetos que cualquiera puede encontrar en un contenedor. El valor del reciclaje, en efecto, es esencial para comprender el dinamismo de la plaza; sin embargo, esos productos reciclados se mezclan con la venta de CD piratas, televisiones, ordenadores o teléfonos móviles robados. Los inmigrantes huyen cuando viene la policía, pero no por el hecho de ser vendedores ambulantes - eso no es ningún delito-, sino porque no tienen papeles y temen ser detenidos. La mayoría son marroquíes.

En el mercado de Les Glòries hay diferentes categorías de empresariado étnico: los fijos del interior ( $y$, entre ellos, los que cambian y los que no cambian de parada), los fijos de la calle Dos de Maig y los de fuera. Los de fuera están «fuera de la ley», «no tienen nada que ver con este mercado, son gente que se busca la vida», nos comentan los vendedores. Los que están dentro, pues, están en situación legal; los que están fuera, en cambio, se encuentran en situación ilegal.

\section{(i) El espacio de la Fira}

Una de las características distintivas de este mercado de Bellcaire es la subasta. Un encargado de la Fira, que va de parada en parada, en principio sin seguir un orden espacial, inicia la puja con un mazo de madera. Normalmente comienza a cantar a partir

3 Avui, 5 de agosto de 2000. «Les Glòries: un viatge d'anada i tornada a les escombraries. La Guàrdia Urbana de Barcelona va decomissar l'any passat 150.000 quilos de material de rebuig del «mercat de la misèria» i els va portar a l'abocador». 
de 4.000 duros. Una vez cerrada la compra, el comprador entrega una paga y señal y recibe un recibo, para que luego pase por la oficina a completar el pago. Lo curioso es que la gente compra los productos de la parada entera: los lotes. Son siempre productos combinados (muebles antiguos, libros viejos...), a los que después se pueden añadir mil cosas, como radios, cacharros pequeños..., todo muy revuelto. En otros lotes hay telas, enchufes en grandes cantidades, mangueras viejas, etc.

No todos los marroquíes pertenecen a la misma escala profesional. Hay muchas categorías: propietario de puesto, comprador, cargador, vendedora ambulante de té, etc. Todos mantienen intensas relaciones de intercambio. Según Youssef, uno de los comerciantes, todos traman «juegos que son ilegales», y pone como ejemplo el tema de los libros. Por la mañana llega un cargamento de libros, parte de los cuales tienen valor intelectual; el resto no vale la pena. Es el comprador del propio mercado quien determina el precio. Así, puede ocurrir que haya un libro valioso, por el que se podrían llegar a pagar 500 euros, precio que el comprador no esté dispuesto a pagar y, por ese motivo, quiera engañar al vendedor. Este tipo de compradores son los compradores con conocimiento, son los que entienden y funcionan como una especie de comunidad; no son sólo españoles, están todos mezclados. «Este mercado, en realidad, es una empresa montada de tal manera que cada uno tiene su parte y se beneficia de ella. Es aquí donde se pueden ver los beneficios que se lleva cada parte, donde se puede ver la verdadera categoría que corresponde a las personas. Por encima de ellos hay otros que son los que dominan, los que llegan a primera hora y dan el precio que quieren, los que imponen los precios. Son los mayores, que conocen bien el valor de las mercancías», añade Youssef.

En general, es un ambiente marcadamente masculino, no sólo por la presencia marroquí, sino también por la española. Los lotes se van revendiendo a lo largo de la mañana, hasta cinco veces. Ése es el verdadero juego de este mercado: los precios y los compradores cambian continuamente. Todos los cargadores son chicos marroquíes.

A partir de la venta de lotes se montan los sublotes. En el transcurso de la subasta se pueden ver las relaciones que existen entre marroquíes y españoles, que aquí están muy mezclados: se compran y se venden entre sí, regatean entre sí y conocen sus respectivos caracteres. Hay vendedores que tienen varias paradas, y ayudantes que pueden trabajar al mismo tiempo para todas ellas; también los hay que trabajan como intermediarios para los anticuarios de fuera. Los clientes son de varios tipos: los hay que van para Barcelona, básicamente a las tiendas de artesanos; los clientes que vienen de Francia y cargan en furgonetas (son, sobre todo, de Perpiñán, Montpellier y, en general, el sur de Francia); compradores europeos, con especial presencia de holandeses e italianos, que cargan en contenedores y camiones... Asimismo, se puede distinguir entre compradores mayoristas, «medios» y particulares. Hay, pues, una extraordinaria 
movilidad transfronteriza tanto por lo que respecta a los compradores como por lo que se refiere a los vendedores.

Dentro y fuera se sitúan, respectivamente, los antiguos y los recién llegados, los con papeles y los sin papeles, los con puesto y los sin puesto, los que pagan impuestos y los que no. Clase social, etnia, género, legalidad o ilegalidad, tiempo de asentamiento, personas solas o con familia..., todas estas características se contraponen en la ubicación de los dos espacios de intercambio. Así, parecen distinguirse dos categorías principales entre los marroquíes: los de la plaza, que se encuentran en una situación más precaria, y los de la Fira, asentados en Cataluña desde hace años, que suelen ir mejor vestidos, tienen más edad, dominan la lengua castellana y tienen mayor nivel de estudios y más savoir faire.

\section{(ii) El mercado informal}

Es el lugar exterior, el lugar donde es posible encontrarlo todo, desde un ordenador portátil o un buen teléfono móvil hasta una muñeca de plástico sin brazos. Los vendedores que se ubican en este espacio se dan cita los días del mercado de los Encants, configurando así un «mercado paralelo». Otra cosa es si van o no siempre esos días, pues combinan sus días laborales de manera absolutamente flexible.

A primera hora de la mañana, cuando la plaza aún se halla cerrada por una verja, los vendedores informales se sitúan en la misma calle en que se extiende la Fira de Bellcaire. Se trata, básicamente, de jóvenes marroquíes que disponen sus telillas en el suelo. También aquí los cambios son continuos. La presencia de la policía y la hora del día son variables, y afectan al valor del producto. Los precios bajan, por ejemplo, al final de la mañana, cuando, además, hay menos competencia, pues muchos vendedores se han marchado después de que la policía haya aparecido en la plaza.

Hay varias mujeres marroquíes asiduas. A diferencia del espacio interno, donde suelen acompañar a sus maridos, están solas en su puesto. Aquí, pues, en la más absoluta informalidad, en situación de precariedad, es donde aparecen verdaderamente como emprendedoras.

En este mercado informal impera el arte de la conversación: bromean, ríen, discuten, hablan sobre sus vidas... Se establece una relación de complicidad entre cliente y mercader, a través de los artilugios del regateo; y también entre mercaderes, en tanto que compatriotas, en tanto que personas que viven una misma situación, por su condición de extranjeros.

Mientras unos venden, otros hurgan continuamente entre los restos de mercancía y basuras, que con frecuencia se confunden. Nora explicaः «Míralos, mujeres y hombres 
solos, que son los recogedores de basuras», personas que hurgan entre los restos que abandonan esos mercaderes informales.

Todo este entramado, en suma, crea un verdadero espacio cosmopolita, donde el regateo relaciona a todos por igual, aunque unos dominen sobre otros en las transacciones del mercado.

\section{4. ¿El mercader del mercado como empresario étnico?}

El empresariado étnico se puede entender en este contexto como una respuesta vinculada a la dificultad para acceder a otro tipo de trabajos, como una estrategia de independencia económica a modo de autodefensa básica frente a la exclusión. Supone una vía abierta para hacer frente a la situación que viven los inmigrantes marroquíes en el mercado secundario. Sin embargo, no se trata de una respuesta uniforme: en unos casos, es un proyecto que responde a objetivos muy precisos; en otros, en cambio, es una reacción a una situación de marginalidad, de exclusión social y de desventajas en el acceso a los recursos fundamentales.

La articulación de la red social resulta de gran importancia, por el peso que tiene en los procesos de llegada, de acceso a la vivienda, de reclutamiento laboral y de construcción de comunidades sólidas. Las redes operan también como fuente básica de información en el acceso al empresariado étnico; una vez montado el negocio, asimismo, operan como lugar de formación. En este sentido, cabe distinguir de nuevo entre los que eran negociantes en origen y los que podríamos llamar «negociantes de la supervivencia», que intentan «buscarse la vida».

El empresariado étnico responde aquí a dos factores esenciales: por una parte, a la necesidad de evitar los mecanismos de discriminación en el mercado de trabajo, a los que cabe sumar una serie de obstáculos que uno puede encontrar para acceder a ese mercado (por ejemplo, la necesidad de contar con una carta de recomendación), pero también a la vivienda. Por otra parte, responde a una necesidad de flexibilidad en la gestión del propio trabajo.

Para los entrevistados, esa flexibilidad se manifiesta en muchos aspectos. En particular, se manifiesta en el lugar que ocupan los mercaderes, que cambian constantemente de posición; y también en el margen que este tipo de trabajo les concede para organizarse a su gusto y en función de sus necesidades y de las de su familia. Así, por ejemplo, al trabajar como autónomos, durante el Ramadán puedan adaptar sus horarios laborales al ritmo del ayuno y las fiestas familiares. 
Flexibilidad e informalidad son las características básicas del contexto en que opera el empresariado étnico en los mercados, fruto de su precaria situación económica. En el caso de los mercados no autorizados y de la venta ambulante clandestina, esa informalidad se mezcla con el mercado de lo ilícito. El capital social denota en todas esas situaciones una fuerza considerable en el desarrollo de las estrategias comerciales. Se trata de una relación de intercambio de carácter mercantil basada en la amistad, en el «compatriotismo», en el hecho de vivir una experiencia común y compartir un mismo espacio social. En ausencia de relaciones contractuales formalizadas, los participantes en el intercambio utilizan como criterio los intercambios basados en la confianza mutua.

Youssef me explica cómo funciona el sistema de ayudas para un recién llegado al mercado interior, el de la Fira de Bellcaire. Los marroquíes no lo ayudan con un préstamo o con capital, sino ofreciéndole trabajo como ayudante en sus puestos. De esta forma, los recién llegados, al tiempo que se insertan en la estructura laboral, aprenden el oficio y la forma de relacionarse en el mercado. Con el paso del tiempo, unos continúan siendo ayudantes y otros empiezan a comprar lotes, si han podido reunir suficiente capital. Los que deciden quedarse como ayudantes saben que la compra de los lotes implica mayores riesgos, pero también mayores beneficios, si las cosas van bien.

Youssef empezó comprando restos, sobre todo trabajando por la tarde. Pudo comprar esos restos porque había traído dinero desde su pueblo. Explica la diferencia que existe entre los vendedores de la mañana y los de la tarde: la gente de la tarde trata «de aprovecharse y engañar»; por la mañana, en cambio, hay negociantes, «gente que sabe», y diferentes categorías de clientes, que entran y salen constantemente. Así pues, no sólo entre espacios y horas, sino también entre la mañana y la tarde se construyen las jerarquías.

La familia M'Rabet, que tiene una tienda y también un puesto en el mercado, desempeña un importante rol comunitario, no sólo porque da de comer a muchas personas que vienen para romper el ayuno de Ramadán a su casa, sino también porque les proporcionan contactos.

Cuando se pregunta por las relaciones comerciales, es frecuente oír la expresión «mi paisano»; no en vano, las relaciones de reciprocidad se basan en la etnicidad. Sin embargo, esas relaciones van más allá, en un continuo conversar con todos, autóctonos y marroquíes, ecuatorianos y otros africanos, clientes e intermediarios... Las relaciones comerciales les permiten ampliar continuamente sus relaciones. Por eso, el savoir faire, el saber tratar con todo tipo de personas, se convierte en una herramienta imprescindible. Esas múltiples relaciones están fuertemente entrelazadas, pero también jerarquizadas. En cualquier caso, la fuente de solidaridad es la familia, o bien aquellos que en el negocio acaban convirtiéndose también en familia: 
«Tengo un morenito que me ayuda a recoger. Ahora es como si fuese de la familia, porque al final en el mundo todos nos volvemos como si fuésemos una familia». «No tiene papeles, pero yo no puedo arreglarlo. Depende del gobierno, no de nosotros», explica Karim.

En estos negocios existe un amplio abanico de fuentes de aprovisionamiento, así como de canales de distribución de la mercancía, tanto lícita como ilícita: artículos defectuosos, artículos de segunda mano, productos comprados a fabricantes, artículos robados, etc. Esa mercancía se intercambia frecuentemente en mercados no institucionalizados que se abastecen en un territorio muy amplio que incluye todas las formas de venta ambulante internacional. La amplia variedad de productos, por otra parte, responde a la flexibilidad que pueden adoptar los mercados paralelos.

En este tipo de mercados encontramos una concepción particular del trabajo, que se deduce de la división entre el mundo del trabajo legítimo y el mundo del trabajo ilegítimo, así como entre el mundo del trabajo formal y el mundo del trabajo informal. A veces se subraya un carácter oportunista y adquisitivo, de «buscarse la vida y de hacer cualquier cosa», que acaba por separarlo conceptualmente de la noción de trabajo o, como mucho, lleva a calificarlo de «pequeño trabajo».

En cuanto al consumo específico de productos étnicos, una de las manifestaciones más claras la constituye la extensión de las carnicerías halal por toda la geografía catalana. En ellas se pueden encontrar los productos alimenticios permitidos por el islam y, en particular, la carne cortada según el ritual islámico, que se ha convertido en compra obligada de todo buen musulmán, al igual que ocurre, por ejemplo, con los peinados afro en las peluquerías dominicanas. Se trata, en fin, de negocios que han surgido de las necesidades específicas de los colectivos de inmigrantes.

Por último, dentro de esos mercados clandestinos cabe referirse al contrabando, o trabendo, de los argelinos. El término trabendo, adaptación árabe dialectológica del término «contrabando», nace a principios de los años ochenta para referirse al mercado negro. El tráfico y los mercados de intercambio de bienes procedentes del contrabando existen en muchas áreas del norte de África: entre España y Marruecos, gracias a los enclaves de Ceuta y Melilla; y en las ciudades de Uxda, Fez y Tánger. En Argelia, al trabendista se le conoce como el «muyaidín de la bolsa»(Colombo, 1998: 71). Es el inmigrante de la bolsa, el inmigrante de la maleta, un tipo distinto de inmigrante, un tipo distinto de empresario poco analizado en los mundos teóricos y empíricos del empresariado étnico. 


\section{Bibliografía}

Beltrán, J.; Oso, L.; Ribas, N. (2007). El empresariado étnico en España. Madrid: Colección Documentos del Observatorio Permanente de la Migración y Editorial Cidob.

Bonacich, E. (1973). «A theory of middleman minorities», American Sociological Review, 38: 583-594.

Соцомво, A. (1998). Etnografia di un'economia clandestina. Immigrati Algerini a Milano. Bologna: Il Mulino.

Geertz, C. (2003). Le souk de Sefrou. Sur l'économie du bazar. Paris: Editions Bouchène.

Granovetter, M. (1985). «Economic Action and Social Structure: the Problem of Embeddedness», American Journal of Sociology, 91 (3): 481-510.

Izquierdo Escribano, A.; Fernández Suárez, B. (2007). «La inmigración en España 2005-06: entre la normalización y el flujo de cayucos», en Navarro, V. (ed.). La situación social en España, Madrid: Biblioteca Nueva - Fundación Largo Caballero, pp. 219-256.

Mermier, F. (2005). «Souk et citadinité dans le monde arabe», en Arnaud, J. L. (dir.). L'urbain dans le monde musulman de la Mediterranée. Paris: Maisonneuve et Larouse, pp. 81-100.

Oso, L. (dir.) (2004). El empresariado étnico como una estrategia de movilidad social para las mujeres inmigrantes en España. Madrid: Instituto de la Mujer.

Portes, A. (1995). «Economic Sociology and the Sociology of Immigration: A conceptual Overview», en Portes, A. The Economic sociology of immigration. Essays on Networks, Ethnicity and Entrepeneurship. New York: Russell Sage Foundation.

Polanyi, K. (1989). La gran transformación. Crítica del liberalismo económico. Madrid: La Piqueta.

Rath, J. (2000). Immigrant Business. The Economic, Political and Social Environment. Basingstoke: MacMillan Press.

Ribas Mateos, N.; Sempere, J. D. (2007). «El negocio de la maleta en Alicante y Tánger: descifrando el circuito mediterráneo», en Beltrán, J;; Oso, L.; Ribas, N. El empresariado étnico en España. Madrid: Colección Documentos del Observatorio Permanente de la Migración y Editorial Cidob.

Solé, C.; Parella, S. (2005). Negocios étnicos. Los comercios de los inmigrantes no comunitarios en Cataluña. Barcelona: Fundació Cidob.

TEIM (1994). «Origen e itinerarios de los inmigrantes marroquíes en Cataluña: de los primeros asentamientos a la regularización», en Colectivo Ioé, Marroquins a Catalunya 
Barcelona: Institut de la Mediterrània, pp. 147-160.

Wilson, K.; Portes, A. (1980). «Immigrant Enclaves: A Comparison of the Cuban and Black Economies in Miami», American Journal of Sociology, 78: 135. 